Review

\title{
Ionic Liquid Crystals in Tribology
}

\author{
M.D. Avilés ${ }^{\mathbb{D}}$, C. Sánchez, R. Pamies ${ }^{\mathbb{D}}$, J. Sanes and M.D. Bermúdez *
}

Grupo de Ciencia de Materiales e Ingeniería Metalúrgica, Universidad Politécnica de Cartagena, Campus de la Muralla del Mar, 30202 Cartagena, Spain

* Correspondence: mdolores.bermudez@upct.es

Received: 3 July 2019; Accepted: 14 August 2019; Published: 21 August 2019

Abstract: The present work intends to provide a brief account of the most recent advances in the use of ionic liquid crystals (ILCs) in the field of tribology, that is, the development of new lubricants with the ability to reduce the coefficients of friction and the wear rates of materials under sliding conditions. After a definition of ILCs and their relationship with neutral liquid crystals (LCs) and ionic liquids (ILs), the review will be focused on the influence of molecular structure and composition on the tribological performance, the combination with base oils, surfactants or water, and the different sliding configuration and potential applications. The main mechanisms proposed in order to justify the lubricating ability of ILCs will be analyzed. Special emphasis will be made for recent results obtained for fatty acid derivatives due to their renewable and environmentally friendly nature.

Keywords: ionic liquid crystals; lubrication; friction; wear

\section{Introduction}

The broad field of liquid crystal materials (LCs) has been an active area of interest for scientists and engineers since the discovery of liquid crystalline behavior by Reinitzer at the end of the 19th century [1]. As shown in Figure 1, the new state of matter combines the properties of solid crystalline materials with those of isotropic liquid fluids.

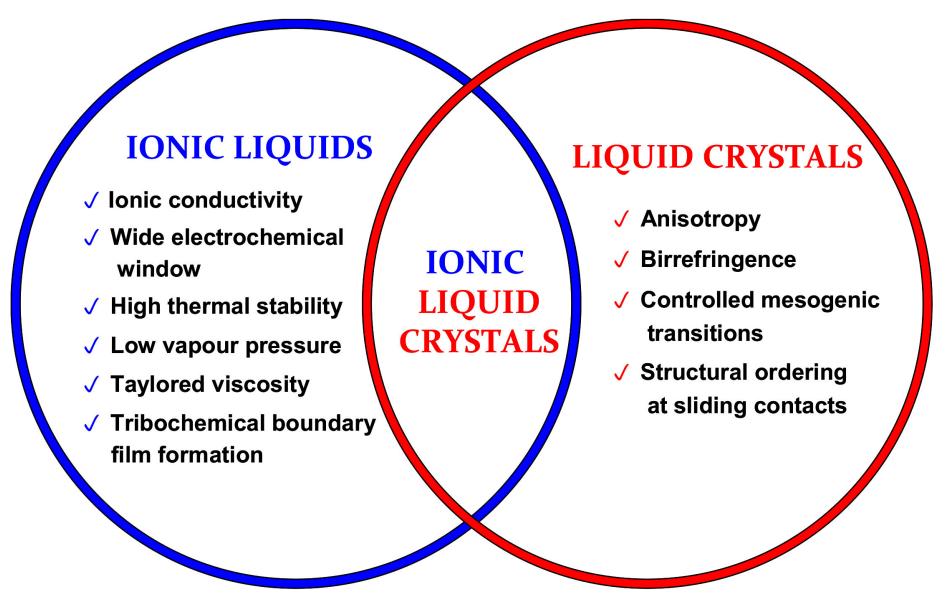

Figure 1. Ionic liquid crystals combine the features of neutral liquid crystals and ionic liquids.

The combination of the liquid crystalline state and the ionic nature of ionic liquids (ILs) produces the new family of ionic liquid crystals (ILCs), which can be defined as ILs with mesogenic behavior [2].

A decade ago, the state of the art of both LCs and ILC in tribology was the subject of two review papers $[3,4]$. Over this period of time, the focus on IL lubricants has somewhat overshadowed the attention on the tribological applications of neutral LCs. Today, the scope of the field has spread to 
new molecular systems, particularly ILCs and more eco-friendly lubricants, based on heteroatom-free additives in aqueous or synthetic media. The use of ILCs in tribology will constitute the basis for the present review.

The annual evolution of scientific publications and citations along the last two decades for ILs in general and ILCs in particular shows an exponential growth.

The global demand for synthetic lubricants is expected to grow at a $5 \%$ annual rate during the next 5 years. Synthetic lubricants are chemically synthesized from petroleum derivatives and include a wide range of synthetic additives in their final commercial formulations. Environmental concerns have boosted the research and development of the so-called biolubricants, which are biodegradable synthetic or vegetable oils and greases.

A recent review on the tribological performance of biolubricants [5] includes vegetable oils and their derivatives, long-chain esters, and polyolesters. This review reports conventional ILs among the eco-friendly additives. Another very recent review on ILs as boundary lubricants [6] does not include ILCs. This shows that the use of the ILC family in tribology has only very recently been the object of attention by researchers $[7,8]$.

Some review articles on thermotropic [8] and lyotropic LCs [9], as well as on ILCs [10], have been previously published, but to the best of our knowledge, this is the first review specifically dedicated to ILCs in tribology and lubrication as surface modifiers, as well as friction-reducing and wear-preventing agents.

\section{Ionic Liquid Crystals}

ILCs are usually composed of cations with a long alkyl chain substituent. For an IL to be transformed in ILC, with stable mesophases, alkyl chain length is a critical factor. For imidazolium ILC derivatives, a critical lateral chain length of at least 12 carbon atoms (Figure 2a) seems to be necessary for mesomorphic behavior, where ordered arrangements of molecules are formed (Figure $2 b$ ).

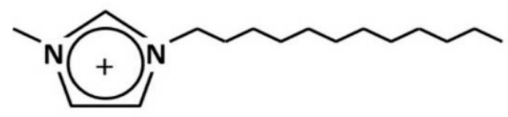

(a)

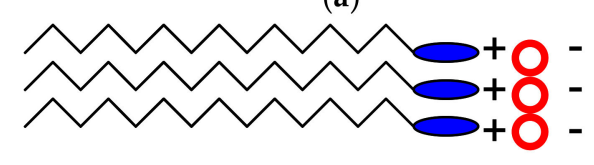

(b)

Figure 2. (a) Imidazolium cation; (b) cation-anion organization in ILCs.

This critical chain length is also a prerequisite for neutral LCs. Other factors present in ILCs are van der Waals interactions between alkyl chains, hydrogen bonds between anionic and cationic moieties, and electrostatic forces between ions [8]. Figure 3 summarizes some cations and anions commonly present in ILs and ILCs, comprising imidazolium, pyridinium, ammonium, phosphonium and guanidinium cations and borates, phosphates (usually in the perfluorinated forms of tetrafluoroborate and hexafluorophosphate), sulfonate, carboxylate, dicyanamide or halide anions.

Weak interactions determine isotropic liquid behavior. In contrast, strong electrostatic, van der Waals or hydrogen bonding interactions are necessary for ILC behavior. Anion-cation electrostatic interactions are a function of anion composition, being stronger in the case of halide anions and weaker for fluorinated anions (Figure 3). 
<smiles>[R]c1c(P)n(P)c([R])[n+]1P</smiles><smiles>Pc1cc[nH+]cc1</smiles><smiles>CN(C)CCO</smiles><smiles>[2H][N+](P)P</smiles><smiles>NC(N)=O</smiles><smiles>[2H][PH](C)([P])C[Te]</smiles><smiles>[R]S(=O)(=O)[O-]</smiles><smiles>[R]C(=O)[O-]</smiles><smiles>N#COC#N</smiles>

Figure 3. Some common cations and anions present in ILCs.

Temperature transition values for thermotropic mesophases [8] depend on processes of aggregation and segregation. These processes lead to different specific molecular ordering rearrangements. Thus, phosphonium ILCs present smectic A phases, where cations and anions form bilayers separated by double layers of lateral alkyl chains, while smectic T mesophases formed by tetragonal layers and hydrophobic chains have been described for ammonium ILCs.

All these factors-lateral chain length, temperature range, and molecular order-determine the final tribological performance of these materials, but also surface interactions and synergy with solvents, surfactants or nanomaterials.

\subsection{Ionic Liquid Crystal Lubricants}

\subsubsection{Chain Length}

ILCs derived from non-toxic renewable resources are particularly useful in green lubrication technologies. The synthesis of bio-based ILCs has been classified as green chemistry because the starting compounds are biocompatible and it produces no secondary or residual reaction products. In order to form stable mesophases, alkyl chain lengths should contain more than 12 carbon atoms, as shown in Figure 4 for imidazolium-derived ILCs.

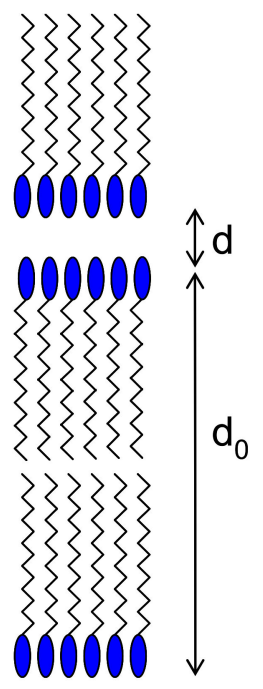

Figure 4. Bilayer and interlayer thickness in self-assembled mesophases (anions not shown for clarity).

In the study of cholesteric mesophases as additives of base oils, Gao et al. [11] have very recently shown that longer perfluoroalkylated chains enlarge the mesogenic temperature range. These additives 
show higher solubility in base lubricant oils and improve tribological performance due to their high thermal stability and formation of thicker lubricant films.

In the case of ILCs, the effect of alkyl chain length on the adsorption on surfaces and on friction reduction was studied by Tariq et al. [12] for alkyl-methylimidazolium chlorides [C(n)mim] $\mathrm{Cl}(n=10$, $12,14)$ on gold surfaces.

One of the potential problems in the use of ILs as lubricants or lubricant additives is that short alkyl chain conventional ILs can be highly hygroscopic [13], but the absorption of water decreases as lateral alkyl chain length increases, as it happens in ILCs [14]. Amann et al. [15], recorded in lubro infrared (IR) spectra in order to study the change in water content during tribological tests using ILs and ILCs, and confirmed the reduction of water content and its influence on corrosion behavior. Friction coefficients lower than 0.02 , after the corresponding running-in periods, were reported.

Pogodina et al. [16] found excellent friction-reducing ability for imidazolium-derived ILCs with a 14-carbon lateral alkyl chain on the imidazolium ring, $\left[\mathrm{C}_{14} \mathrm{mim}\right](\mathrm{mim}=$ methylimidazolium $)$, and different fluorinated anions such as $\mathrm{BF}_{4}, \mathrm{PF}_{6}$ and $\left(\mathrm{CF}_{3} \mathrm{SO}_{2}\right)_{2} \mathrm{~N}$, which belong to the most commonly used anions (Figure 5).

(a)

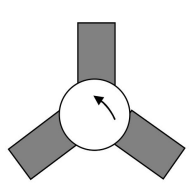

(d)

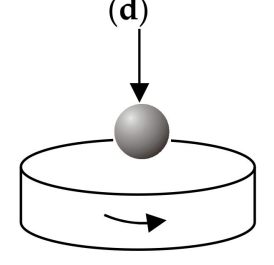

(b)

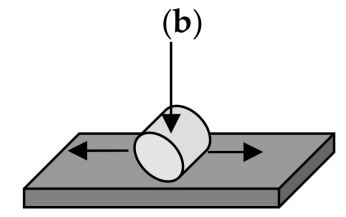

(c)
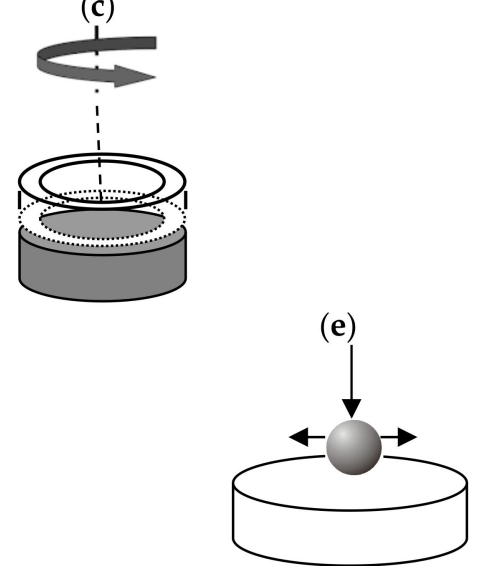

Figure 5. Some common sliding contact configurations used in tribological tests with ILC lubricants: (a) rotating ball on three plates (top view); (b) reciprocating cylinder disk; (c) ring-on-disk; (d) ball or pin on disk (rotational); (e) ball or pin on disk (reciprocating).

Molecular ordering and tribochemical interactions are two decisive factors in ILC tribology. The use of ILC lubricants is not limited to their mesomorphic transition range. In fact, it has been found that thermotropic transitions to form ordered mesophases take place at interfaces due to temperature increase caused by friction.

Zhang et al. [17] have described this behavior for $\left[\mathrm{C}_{16} \mathrm{mim}\right] \mathrm{BF}_{4}$, where the ordering of the long alkyl chain forms a mesomorphic structure adsorbed on the metal surface. This structure would be responsible for the improved load-carrying ability. Friction and wear reduction are also related to tribochemical reactions between ILC molecules and metal surfaces which produce a series of ceramic phases such as boron oxide and iron fluorides. This tribofilm layer would also be responsible for the good tribological performance of $\left[\mathrm{C}_{16} \mathrm{mim}_{\mathrm{BF}}\right.$, when used as additive of base lubricant oils such as liquid paraffin. 
$\left[\mathrm{C}_{14} \mathrm{mim}\right] \mathrm{BF}_{4}$ presented an ultra-low friction coefficient, both in the LC state and in the isotropic liquid state. This is attributed to the formation of a double-layer structure on the surface, where the long alkyl chains of the cations would adopt a parallel highly ordered arrangement.

This bilayer structure would be able to maintain a highly ordered molecular orientation even under shear conditions. Small-angle X-ray scattering (SAXS) confirmed the formation of a smectic phase due to the ordered 14-carbon alkyl chain substituents of the cation moieties. ILC domains parallel to flow under severe shear conditions would be responsible for the low friction coefficients, not only within the mesomorphic range, but also in the isotropic temperature range, thus widening their practical application range.

\subsubsection{Fatty Acids and Other Combinations and Synergistic Effects}

Lyotropic LC phases have been found in protic ionic liquids (PILs) derived from long-chain fatty acids in combination with ethanolamines [18]. Tadokoro et al. [19] described the adsorption of fatty acid molecules on surfaces. According to Gusain et al. [20], the tribochemical reaction between the carboxylic group of fatty acid molecules and the metal surfaces forms a boundary layer with low shear strength. This thin layer would be responsible for the reduction of friction and wear under boundary lubrication conditions.

Toledo et al. [21] have recently described the mesomorphic and rheological properties of 20 PILs containing anions derived from fatty acids, which are present in vegetable oils and cations from 2-hydroxymethylamines. The simple synthetic route of these new low-toxicity, biodegradable PILs [22, 23] has made readily available the use of protic ionic liquid crystals (PILCs) with long chain carboxylate species, with promising tribological properties, both as neat lubricants and as additives [24-26].

Protic ammonium carboxylates, including long-chain carboxylate PILCs, have been recently used to develop new renewable aqueous lubricants obtained by solution or dispersion in water, as themselves, or in combination with nanomaterials $[25,26]$. The 1 wt \% PILC reduces the friction coefficient of water up to $80 \%$. Moreover, when water evaporates due to temperature increase at the sliding contact, the thin PILC layer maintains low friction values and reduces wear by preventing the severe oxidation of steel, which takes place for PILC-free water lubrication. If water is modified by the addition of a dispersion of nanodiamonds in PILC, wear rates reduce by more than two orders of magnitude [26], due to the enhanced load-carrying ability of the PILC-nanodiamonds hybrid lubricant. To ensure the long-term stability of these dispersions would be a previous condition for their practical applications.

Following a related research line, lamellar LCs formed by equimolar aqueous blends of tetradecyltrimethylammonium oxide and oleic acid form ordered hydrophobic domains, which in combination with C-60 fullerene could act as an environmentally friendly lubricant [27].

As both conventional neutral thermotropic LCs and fatty acid have shown their potential as lubricants or lubricant additives, very recently Tadokoro et al. [28] have shown the synergistic effect that takes place when fatty acids are used as additives of a nematic cyanobiphenyl LC. The mixture affords lower friction coefficients than any of the lubricants when they are used separately. A possible mechanism for this synergistic effect is that fatty acid molecules interact with surfaces, changing the surface topography. At the same time, these surface topography changes favor the adsorption of neutral LC molecules. The combined effect increases the effective viscosity of the boundary lubricating layer.

Lu et al. [29] have also explored the use of fatty acids in association by hydrogen-bonding with other molecules, in particular oleic acid and p-pentylbenzoic acid, as lubricant additives. The main effects were an increase of viscosity and a decrease of the traction coefficient in elastohydrodynamic (EHL) and boundary lubrication regimes. The lower friction coefficient was attributed to an alignment of the molecules parallel to the shearing force, as determined micro FTIR (Fourier transformed infrared) spectroscopy.

Long alkyl chain imidazolium salts with fluorinated anions have also been used in combination with lamellar LCs [30,31]. A decreasing thickness of the self-assembled bilayer ordered structure $\left(d_{0}\right)$ 
and an increasing interlayer separation distance (d) (Figure 4) have been related to better lubrication and wear preventing results [31].

In the case of hexagonal lyotropic LC phases, the increase in d spacing has also been achieved by the introduction of manganese (II) species, without destroying their structure [32], or by addition of carbon nanophases such as multiwalled carbon nanotubes (MWCNTs) [33].

Dai et al. [34] described the formation of a lamellar LC structure by combination of the short alkyl chain IL $\left[\mathrm{C}_{4} \mathrm{mim}_{\mathrm{PF}}\right.$, a trioleate surfactant and water. When the proportion of $\left[\mathrm{C}_{4} \mathrm{mim}\right] \mathrm{PF}_{6}$ is increased, the lubricating ability improves. As in previous cases, the load-carrying and wear-reducing ability of the mesophase is further improved by the addition of nanophases, in this case, silver nanoparticles.

\subsubsection{Rheology}

An important issue for all lubricants, or lubricant additives, is their rheology. This reaches a paramount relevance in the case of ordered fluids. The dependence of viscosity with shear, velocity, and temperature should be established and related with tribological performance.

A non-Newtonian viscosity behavior has been described for ILCs. Thus, cholesteric decanoate, valerate, and myristate species show non-Newtonian viscosity values when they are in their cholesteric mesophases range [35].

Amann et al. [36] have confirmed this non-Newtonian viscosity for imidazolium ILCs as well. They have shown that both rheological properties and tribological performance are determined by ILC molecular orientation. This molecular orientation can be modified by shear, thus influencing friction coefficient values, which reach values as low as 0.02 . These authors also found that friction coefficient values are not only a function of molecular orientation, but also of the chemical composition of the anion.

These results show that there still remains a very relevant research effort to be made in the optimization of ILCs chemistry and molecular design.

\subsection{Sliding Configurations and Applications}

Most experimental studies on ILCs lubricants apply standard configurations where the lubricants are added on the surfaces or the sliding materials are immersed in the lubricant. The main objectives are to measure friction coefficients, wear rates, contact electrical resistance, and film thickness.

Some sliding configurations used for the study of the tribological performance of ILCs [25,26,37-39] are shown in Figure 5. Sliding materials are usually metal alloys, in particular bearing steel, and technical ceramics such as alumina.

One of the main challenges for ILC lubricants is the transition from laboratory tests to industrial applications. Among the most recent applications of LCs, Amann et al. [37] have described the use of ILs in infiltrated sintered bearings, in reciprocating cylinder-disk, rotating ball-on-3-plates, and radial bearing.

Elemsimit et al. [40] have proposed a biohydraulic oil where the ILC acts as wear-preventing additive of a canola oil derived lubricant. However, friction coefficient reduction was not achieved in this case with respect to the base oil.

The performance of ILC lubricants is due to a complex combination of variables. Under the tribosystem conditions, contact temperature, sliding velocity, and applied pressure can alter the molecular orientation and the stability range of the mesophases. Thus, outside the tribosystem, ILCs could be in the solid or isotropic states, but form adsorbed oriented mesomorphic domains in the lubricant film.

Another aspect to be considered in the selection of ILC lubricants is their chemical composition. Tribochemical interactions and the formation of protective tribolayers could reduce wear, while ordered fluids would increase lubricant film thickness. 


\section{Conclusions}

Ionic liquid crystals combine the strong polar nature of ILs with the self-organized structure of LCs. This combination of properties is beginning to be exploited in tribology due to the advantages in load-carrying ability, formation of tribolayers after interaction with the sliding surfaces, energy-saving through the reduction of friction coefficients, and wear rates of sliding materials.

A long lateral chain with at least 12 carbon atoms seems a necessary condition for the formation of mesomorphic structures in ILCs. Another important structural parameter is the spacing between bilayer structures. The combination of ILCs with nanomaterials has been proposed as a way to increase interlayer spacing.

The variety of anion and cation compositions, lateral substituents, and self-organization in different base fluids, make it necessary to dedicate a considerable effort in order to elucidate the optimum combination for each practical application.

For ILCs to be competitive in the field of lubrication and tribology, they should be effective not only as neat lubricants but also as additives of other fluids such as water and mineral or synthetic oils.

Although the cost of production of some families of ILCs, such as imidazolium derivatives, is still too high to be competitive with commercial lubricant additives, new ILCs based upon simple synthetic routes have emerged. This could be the case of ammonium carboxylate species obtained by direct reaction between amines and carboxylic acids.

Most promising are the possibilities of development and application of non-contaminant, biocompatible ILCs, however, some challenges remain, such as increasing thermal stability and solubility, or controlling tribochemical interactions at the interfaces.

Funding: The authors acknowledge the Ministerio de Economia, Industria y Competitividad and Agencia Estatal de Investigación (MINECO; AEI, Spain), and the EU FEDER Program (Grant \# MAT2017-85130-P), M.D. Aviles and C. Sanchez are grateful for research grants \# BES-2015-074836 and PRE2018-083774. "Este trabajo es resultado de la actividad desarrollada en el marco del Programa de Ayudas a Grupos de Excelencia de la Region de Murcia, de la Fundacion Seneca, Agencia de Ciencia y Tecnologia de la Region de Murcia (Grant \# 19877/GERM/15)".

Conflicts of Interest: The authors declare no conflict of interest.

\section{References}

1. Mitov, M. Liquid-crystal science from 1888 to 1922: Building a revolution. ChemPhysChem 2014, 15, 1245-1250. [CrossRef]

2. Goosens, K.; Lava, K.; Bielawski, C.W.; Binnemans, K. Ionic liquid crystals: Versatile materials. Chem. Rev. 2016, 8, 4643-4807. [CrossRef]

3. Carrión, F.J.; Martínez-Nicolás, G.; Iglesias, P.; Sanes, J.; Bermúdez, M.D. Liquid crystals in tribology. Int. J. Mol. Sci. 2009, 10, 4102-4115. [CrossRef] [PubMed]

4. Bermúdez, M.D.; Jiménez, A.E.; Sanes, J.; Carrión, F.J. Ionic liquids as advanced lubricant fluids. Molecules 2009, 14, 2888-2908. [CrossRef] [PubMed]

5. Chan, C.H.; Tang, S.W.; Mohd, N.K.; Lim, W.H.; Yeong, S.K.; Idris, Z. Tribological behaviour of biolubricant basestocks and additives. Renew. Sustain. Energy Rev. 2008, 93, 145-147. [CrossRef]

6. Gong, X.; Li, L. Nanometer-thick ionic liquids as boundary lubricants. Adv. Eng. Mater. 2018, 20, 1700617. [CrossRef]

7. Iglesias, P.; Bermúdez, M.D.; Carrión, F.J.; Martínez-Nicolás, G. Friction and wear of aluminium-steel contacts lubricated with ordered fluids-neutral and ionic liquid crystals as oil additives. Wear 2004, 256, 386-392. [CrossRef]

8. Axenov, K.V.; Laschat, S. Thermotropic liquid crystals. Materials 2011, 4, 206-259. [CrossRef] [PubMed]

9. Huang, Y.; Gui, S. Factors affecting the structure of lyotropic liquid crystals and the correlation between structure and drug diffusion. RSC Adv. 2018, 8, 6978-6987. [CrossRef]

10. Binnemans, K. Ionic liquid crystals. Chem. Rev. 2005, 105, 4148-4208. [CrossRef]

11. Gao, Y.M.; Jiang, Y.; Hu, W.J.; Jiang, H.Z.; Li, J.S. Cholesteryl liquid crystals as oil-based lubricant additives: Effect of mesogenic phases and structures on tribological characteristics. Langmuir 2019, 35, 6981-6992. [CrossRef] 
12. Tariq, M.; Serro, A.P.; Colaco, R.; Saramago, B.; Lopes, J.N.C.; Rebelo, L.P.N. Effect of alkyl chain length on the adsorption and frictional behviour of 1-alkyl-3-methylimidazolium chloride ionic liquid surfactants on gold surfaces. Coll. Surf. A. Physicochem. Eng. Asp. 2011, 377, 361-366. [CrossRef]

13. Plechkova, N.V.; Seddon, K.R. Applications of ionic liquids in the chemical industry. Chem. Soc. Rev. 2008, 37, 123-150. [CrossRef] [PubMed]

14. Cuadrado-Prado, S.; Domínguez-Pérez, M.; Rilo, E.; García-Garabal, S.; Segado, L.; Franjo, C.; Cabeza, O. Experimental measurement of the hygroscopic grade on eight imidazolium based ionic liquids. Fluid Phase Equil. 2009, 278, 36-40. [CrossRef]

15. Amann, T.; Dold, C.; Kailer, A. Complex fluids in tribology to reduce friction: Mesogenic fluids, ionic liquids and ionic liquid crystals. Tribol. Int. 2013, 65, 3-12. [CrossRef]

16. Pogodina, N.V.; Amann, T.; Dold, C.; Metwalli, E.; Müller-Buschbaum, P.; Kailer, A.; Friedrich, C. Triborheology and orientational dynamics of ionic liquid crystals. J. Mol. Liq. 2014, 192, 118-126. [CrossRef]

17. Zhang, C.; Zhang, S.; Yu, L.; Zhang, P.; Zhang, Z.; Wu, Z. Tribological behavior of 1-methyl-3-hexadecylimidazolium tetrafluoroborate ionic liquid crystal as a neat lubricant and as an additive of liquid paraffin. Tribol. Lett. 2012, 46, 49-54. [CrossRef]

18. Maximo, G.J.; Sanos, R.J.B.N.; Lopes, J.A.; Costa, M.C.; Meirelles, A.J.A.; Coutinho, J.A.P. Lipidic protic ionic liquid crystals. ACS Chem. Eng. 2014, 2, 672-682. [CrossRef]

19. Tadokoro, C.; Araya, S.; Okubo, H.; Nakano, K. Polarization observation of adsorption behaviour of fatty acids using optical anisotropy of liquid crystal. Tribol. Lett. 2016, 64, 30. [CrossRef]

20. Toledo, A.A.C.; Maximo, G.J.; Costa, M.C.; Cunha, R.L.; Pereira, J.F.B.; Kurnia, K.A.; Batista, E.A.C.; Meirelles, A.J.A. Phase behaviour and physical properties of new biobased ionic liquid crystals. J. Phys. Chem. B 2017, 121, 3177-3189. [CrossRef] [PubMed]

21. Gusain, R.; Khatri, O.P. Fatty acid ionic liquids as environmentally friendly lubricants for low friction and wear. RSC Adv. 2016, 6, 3462-3469. [CrossRef]

22. Santos, D.; Costa, F.; Franceschi, E.; Santos, A.; Dariva, C.; Mattedi, S. Synthesis and physico-chemical properties of two protic ionic liquids based on stearate anion. Fluid Phase Equilibria 2014, 378, 132-140. [CrossRef]

23. Álvarez, S.; Mattedi, M.; Martín-Pastor, M.; Aznar, M.; Iglesias, M. Synthesis and thermophysical properties of two new protic long-chain ionic liquids with the oleate anion. Fluid Phase Equilibria 2010, 299, 354-366. [CrossRef]

24. Shi, Y.; Larsson, R. Non-corrosive and biomaterials protic ionic liquids with high lubricating performance. Tribol. Lett. 2016, 63, 1. [CrossRef]

25. Avilés, M.D.; Carrión, F.J.; Sanes, J.; Bermúdez, M.D. Effects of protic ionic liquid crystal additives on the water lubricated sliding wear and friction of sapphire against stainless steel. Wear 2018, 408, 56-64. [CrossRef]

26. Carrión, F.J.; Avilés, M.D.; Nakano, K.; Tadokoro, C.; Nagamine, T.; Bermúdez, M.D. Diprotic ammonium palmitate ionic liquid crystal and nanodiamonds in aqueous lubrication. Film thickness and influence of sliding speed. Wear 2019, 418, 241-252. [CrossRef]

27. Chen, M.; Liu, B.; Wang, X.; Fu, Y.; Hao, J.; Li, H. Zero-charged catanionic lamellar liquid crystals doped with fullerene C60 potential applications in tribology. Soft Matter 2017, 13, 6250-6258. [CrossRef]

28. Tadokoro, C.; Araya, S.; Watanabe, M.; Okubo, H.; Sasaki, S. Synergy of two fatty acids as additives on lubricity of a nematic liquid crystal 5CB. Lubr. Sci. 2018, 30, 83-90. [CrossRef]

29. Lu, R.; Mori, S.; Tani, H.; Tagawa, N.; Koganezawa, S. Low friction properties of associated carboxylic acids induced by molecular orientation. Tribol. Int. 2017, 113, 36-42. [CrossRef]

30. Chen, L.; Ge, L.; Fan, L.; Guo, R. Microstructure and tribological properties of lamellar liquid crystals formed by ionic liquids as co-surfactants. Langmuir 2019, 35, 4037-4045. [CrossRef]

31. Chen, L.; Han, J.; Ge, L.; Fan, L.; Guo, R. Improvement in lubricating properties of TritonX-100/n- $\mathrm{C}_{10} \mathrm{H}_{21} \mathrm{OH} / \mathrm{H}_{2} \mathrm{O}$ lamellar liquid crystals with the amphiphilic ionic liquid 1-alkyl-3-methylimidazolium hexafluorophosphate. J. Coll. Interface Sci. 2018, 522, 200-207. [CrossRef] [PubMed]

32. Jiang, W.Q.; Liu, P.; Hao, J.C. Polyoxometalate-lyotropic liquid crystal hybrid material in room-temperature ionic liquids. J. Nanosci. Nanotechnol. 2011, 11, 2168-2174. [CrossRef]

33. Jiang, W.; Yu, b.; Liu, W.; Hao, J. Carbon nanotubes incorporated within lyotropic hexagonal liquid crystal formed in room-temperature ionic liquids. Langmuir 2007, 23, 8549-8553. [CrossRef] [PubMed] 
34. Dai, T.; Ge, L.L.; Guo, R. Microstructure of lamellar liquid crystal in Tween $85 /[\mathrm{Bmim}] \mathrm{PF}_{6} / \mathrm{H}_{2} \mathrm{O}$ system and applications as Ag nanoparticle synthesis and lubrication. J. Mater. Res. 2009, 24, 333-341. [CrossRef]

35. Madhavi, A.B.; Sastry, S.S. Rheological properties of cholesteric liquid crystals as lubricant additives. Int. J. Modern Phys. B 2019, 33, 1950014. [CrossRef]

36. Amann, T.; Dold, C.; Kailer, A. Rheological characterization of ionic liquid crystals with promising tribological performance. Soft Matter 2012, 8, 9840-9846. [CrossRef]

37. Amann, T.; Kailer, A.; Beyer, S.; Stehr, W.; Metzger, B. Development of sintered bearings with minimal friciton losses and maximum lifetime using infiltrated liquid crystalline lubricants. Tribol. Int. 2016, 98, 282-291. [CrossRef]

38. Moksin, V.; Kilikevicius, A.; Vekteris, V. Investigation of dissipative properties of liquid crystalline lubricant layer. J. Vibroeng. 2012, 14, 502-508.

39. Amann, T.; Kailer, A. Analysis of the ultralow friction behaviour of a mesogenic fluid in a reciprocating contact. Wear 2011, 271, 1701-1706. [CrossRef]

40. Elemsimit, H.A.; Grecov, D. Impact of liquid crystal additives on a canola oil-based bio-lubricant. Part J J. Eng. Tribol. 2015, 229, 126-135. [CrossRef]

(C) 2019 by the authors. Licensee MDPI, Basel, Switzerland. This article is an open access article distributed under the terms and conditions of the Creative Commons Attribution (CC BY) license (http://creativecommons.org/licenses/by/4.0/). 